\title{
Protective effect of magnesium on the endothelial function mediated by endothelium-derived hyperpolarizing factor in coronary arteries during cardioplegic arrest in a porcine model
}

Oin Yang, MD, MPH, ${ }^{a}$ Yao-Chung Liu, MD, ${ }^{a}$ Wei Zou, MD, ${ }^{a}$ Anthony P. C. Yim, MD, a and Guo-Wei He, MD, PhD ${ }^{\mathrm{a}, \mathrm{b}}$

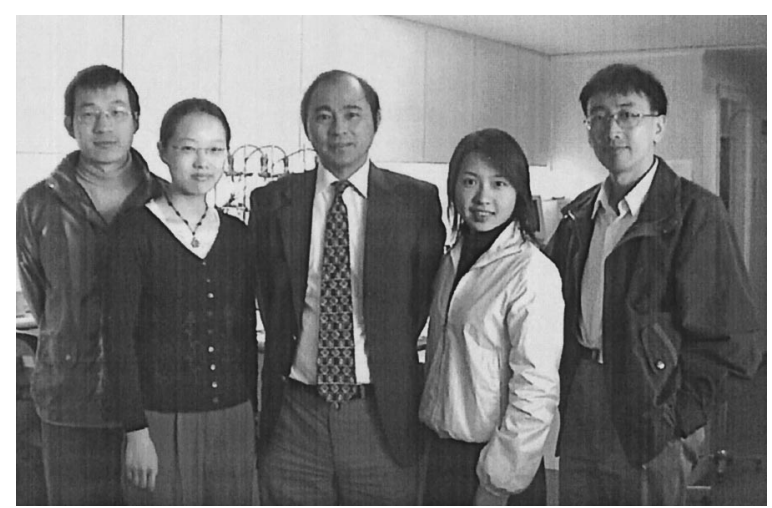

Objectives: Hyperkalemia in cardioplegia impairs the function mediated by endothelium-derived hyperpolarizing factor. This study examined the effect and mechanism of magnesium ion on the relaxation mediated by endothelium-derived hyperpolarizing factor.

Methods: In the isometric force study, porcine coronary microarteries in a myograph (diameter $200-450 \mu \mathrm{m}$ ) were incubated in Krebs solution (subgroups Ia, IIa, and IIIa), potassium ion (20 $\mathrm{mmol} / \mathrm{L}$, subgroups $\mathrm{Ib}$, IIb, and IIIb), magnesium ion $(16 \mathrm{mmol} / \mathrm{L}$, subgroups Ic, IIc, and IIIc), or potassium ion plus magnesium ion (subgroups Id, IId, and IIId) for 1 hour at $37^{\circ} \mathrm{C}$ in group I or II, followed by washout for 45 minutes in group III $(\mathrm{n}=8)$. Relaxation to bradykinin (groups I and III) or sodium nitroprusside (group II) in $\mathrm{U}_{46619}$-stimulated contraction was established. In the electrophysiologic study, the membrane potentials of single smooth muscle cells of arteries were measured by microelectrode after superfusion with the previously described solutions (subgroups IVa-IVc).

From the Division of Cardiothoracic Surgery, Department of Surgery, The Chinese University of Hong Kong, Hong Kong SAR, China, ${ }^{a}$ and Providence Heart Institute, Albert Starr Academic Center, the Department of Surgery, Oregon Health \& Science University, Portland, Ore. ${ }^{\mathrm{b}}$

Supported in full by grants from the Research Grant Council of the Hong Kong Special Administrative Region (Projects CUHK7246/99M and CUHK4127/01M), China, and the Providence St Vincent Medical Foundation, Portland, Ore.

Received for publication July 23, 2001; revisions requested Sept 12, 2001; revisions received Dec 20, 2001; accepted for publication Dec 27, 2001.

Address for reprints: Guo-Wei He, MD, $\mathrm{PhD}$, Department of Surgery, Block B, 5A, Prince of Wales Hospital, The Chinese University of Hong Kong, Shatin, NT, Hong Kong SAR, China (E-mail: gwhe@cuhk. edu.hk.).

J Thorac Cardiovasc Surg 2002;124:361-70

Copyright (C) 2002 by The American Association for Thoracic Surgery

0022-5223/2002 $\$ 35.00+0 \quad \mathbf{1 2 / 1 / 1 2 2 5 4 8}$

doi:10.1067/mtc.2002.122548
Results: In group I, 20-mmol/L potassium ion greatly reduced the bradykinininduced relaxation $(35.0 \% \pm 4.9 \%$ vs $86.0 \% \pm 5.3 \%, P<.001)$, which was significantly restored by magnesium ion $(51.9 \% \pm 4.0 \%, P=.017)$. In groups II and III, the bradykinin- or nitroprusside-induced relaxation had no significant differences. In group IV, potassium ion depolarized the smooth muscle and decreased the bradykinin-induced hyperpolarization $(-72.0 \pm 1.5$ vs $-61.7 \pm 0.7$ $\mathrm{mV}, \mathrm{n}=7, P<.001$ ), which was significantly restored by magnesium ion $(-68.0 \pm 2.5 \mathrm{mV}$ vs $-72.5 \pm 1.5 \mathrm{mV}, \mathrm{n}=6, P=.029)$.

Conclusions: Magnesium ion, either alone or added to hyperkalemic solutions, preserves or helps to restore the endothelial function mediated by endotheliumderived hyperpolarizing factor. The mechanism is related to preservation of the membrane hyperpolarization and reversal of the potassium-induced membrane depolarization of the smooth muscle cell.

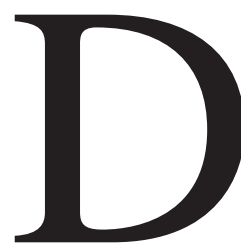

epolarizing cardioplegia is widely used in cardiac surgery to arrest the heart and protect it from subsequent ischemia-reperfusion injury. ${ }^{1}$ The major depolarizing agent in these cardioplegic solutions is potassium at high concentrations (hyperkalemia), usually 10 to $20 \mathrm{mmol} / \mathrm{L} .{ }^{1}$ Previous studies have shown that hyperkalemia causes damage to arterial endothelial function. ${ }^{2-4}$

Endothelium exerts an important modulatory effect on vascular tone. Endothelium-dependent relaxation is known to be caused by a variety of endotheliumderived relaxing factors. These are endothelium-derived nitric oxide, prostacyclin 
$\left(\mathrm{PGI}_{2}\right)$, and endothelium-derived hyperpolarizing factor (EDHF) ${ }^{5,6}$ Because of the complexity of endothelial function, it is necessary to study the functions of individual endothelium-derived relaxing factors to find the "perfect" method to preserve the endothelium during cardiac surgery. EDHF-mediated endothelial function plays an important role in the coronary circulation as the backup for nitric oxide, particularly in the coronary microarteries. ${ }^{7}$

On the basis of these considerations, our laboratory has demonstrated that hyperkalemia alters EDHF-mediated relaxation and hyperpolarization (the electrophysiologic basis of mechanical relaxation) in both porcine and human coronary conduit arteries. ${ }^{6,8,9}$ Most recently, we have found that this is also true in porcine coronary microarteries. ${ }^{10}$

Apart from potassium, magnesium is another important ion in either crystalloid ${ }^{11}$ or blood ${ }^{12,13}$ cardioplegia. For example, St Thomas' Hospital solution contains 16-mmol/L magnesium ion. It has been reported that addition of magnesium to the cardioplegic solution is beneficial in myocardial protection. ${ }^{11}$ Moreover, in blood cardioplegia, magnesium ion is also suggested to be supplemented to relieve cardiac injury. ${ }^{12,13}$ Although much is known about magnesium's favorable effect on cardiac myocytes, little is known about its effect on endothelial function. Although there is evidence that hypermagnesemic cardioplegia is superior to hyperkalemic cardioplegia in preserving endotheliumdependent relaxation in porcine coronary microvessels, ${ }^{14}$ the effects of magnesium ion on EDHF-mediated relaxation and hyperpolarization have not been reported. We have previously observed that vascular tone increases during incubation with potassium ion at 16 to $20 \mathrm{mmol} / \mathrm{L}$ but remains almost normal during incubation with St Thomas Hospital cardioplegia. ${ }^{15}$ We therefore hypothesized that the normal vascular tone during incubation with the St Thomas Hospital cardioplegia solution is due to the reversal effect of the magnesium ion contained in that solution and thus that magnesium ion may have a protective effect on EDHFmediated relaxation and hyperpolarization. To test this hypothesis, this study was designed to investigate the effects of magnesium ion and its interaction with potassium ion on EDHF-mediated relaxation and hyperpolarization induced by bradykinin in porcine coronary arteries.

\section{Material and Methods}

\section{Relaxation Studies}

Fresh porcine hearts collected from a local slaughterhouse were placed in a container filled with cold Krebs solution and immediately transferred to the laboratory. Once a heart was received, intramyocardial coronary microarteries (usually the tertiary branches of the left anterior descending artery, diameter 200-450 $\mu \mathrm{m})$ were carefully dissected and removed under a microscope. The vessels were cleaned of fat and connective tissue and cut into cylindrical rings $2 \mathrm{~mm}$ in length under a microscope. The Krebs solution was aerated with a gas mixture of $95 \%$ oxygen and $5 \%$ carbon dioxide at $37^{\circ} \mathrm{C}$ and had the following composition: 118.4$\mathrm{mmol} / \mathrm{L}$ sodium chloride, $4.7-\mathrm{mmol} / \mathrm{L}$ potassium chloride, 1.2$\mathrm{mmol} / \mathrm{L}$ magnesium sulfate, $1.2-\mathrm{mmol} / \mathrm{L}$ potassium phosphate, 25-mmol/L sodium hydrogen carbonate, 11.1-mmol/L (+)glucose, and $2.5-\mathrm{mmol} / \mathrm{L}$ calcium chloride. This solution contains the following final ionic concentrations: $143.4-\mathrm{mmol} / \mathrm{L}$ sodium ion, 5.9- $\mathrm{mmol} / \mathrm{L}$ potassium ion, 2.5- $\mathrm{mmol} / \mathrm{L}$ calcium ion, 1.2$\mathrm{mmol} / \mathrm{L}$ magnesium ion, $128.7-\mathrm{mmol} / \mathrm{L}$ chloride ion, $25-\mathrm{mmol} / \mathrm{L}$ hydrogen carbonate ion, $1.2-\mathrm{mmol} / \mathrm{L}$ sulfate ion, $1.2-\mathrm{mmol} / \mathrm{L}$ phosphate ion, and 11.1-mmol/L glucose.

During the preceding procedure, the endothelium was intentionally preserved by cautiously dissecting and mounting the rings. After the rings were mounted in a four-channel myograph (model 610A; J.P. Trading, Aarhus, Denmark), a previously described method ${ }^{6,10}$ was used to normalize vascular rings under a condition simulating the transmural pressure encountered in vivo in the coronary microartery. Briefly, the artery rings were progressively stretched until the passive transmural pressure reached $100 \mathrm{~mm}$ $\mathrm{Hg}$. The internal circumference was then set to a normalized value, estimated to be equivalent to $90 \%$ of the circumference at a passive transmural pressure of $100 \mathrm{~mm} \mathrm{Hg}$. This pressure was maintained throughout the experiments.

Protocols. All rings were equilibrated for 30 minutes before and after normalization. The following protocols were used.

Group I ( $\mathrm{N}=8$ IN EACH SUBGROUP). Effect of potassium ion ( 20 $\mathrm{mmol} / \mathrm{L})$ or magnesium ion $(16 \mathrm{mmol} / \mathrm{L})$ on endothelium-derived hyperpolarizing factor-mediated relaxation in microarteries.

Four rings taken from the same artery were allocated into four groups. The arterial rings were incubated with four different solutions for 1 hour at $37^{\circ} \mathrm{C}$ : subgroup Ia, Krebs solution as a control; subgroup Ib, potassium ion $(20 \mathrm{mmol} / \mathrm{L})$; subgroup Ic, magnesium ion $(16 \mathrm{mmol} / \mathrm{L})$; and subgroup Id, potassium ion $(20 \mathrm{mmol} / \mathrm{L})$ plus magnesium ion $(16 \mathrm{mmol} / \mathrm{L})$. In these high-potassium or high-magnesium solutions, sodium was replaced with the equivalent potassium or magnesium form. In $20-\mathrm{mmol} / \mathrm{L}$ potassium ion solution, 14-mmol/L sodium chloride was replaced with 14$\mathrm{mmol} / \mathrm{L}$ potassium chloride. In $16-\mathrm{mmol} / \mathrm{L}$ magnesium ion solution, $29.6-\mathrm{mmol} / \mathrm{L}$ sodium chloride $(14.8 \times 2)$ was replaced with $14.8-\mathrm{mmol} / \mathrm{L}$ magnesium sulfate. In the combined $20-\mathrm{mmol} / \mathrm{L}$ potassium ion and 16-mmol/L magnesium ion solution, 43.6$\mathrm{mmol} / \mathrm{L}$ sodium chloride $(14+14.8 \times 2)$ was replaced with $14-\mathrm{mmol} / \mathrm{L}$ potassium chloride and $14.8-\mathrm{mmol} / \mathrm{L}$ magnesium sulfate. The osmolarity therefore remained unchanged.

Inhibitors for $\mathrm{PGI}_{2}$ and nitric oxide were then added into the chamber. They were as follows: indomethacin $(7 \mu \mathrm{mol} / \mathrm{L}$, a cyclooxygenase inhibitor), $\mathrm{N}^{\mathrm{G}}$-nitro-L-arginine (L-NNA, $300 \mu \mathrm{mol} / \mathrm{L}$, a nitric oxide synthase inhibitor), and oxyhemoglobin $(20 \mu \mathrm{mol} / \mathrm{L}$, a nitric oxide scavenger). The arteries were contracted with $\mathrm{U}_{46619}$ in varying amounts $(-8.4 \log \mathrm{mol} / \mathrm{L}$ for subgroup $\mathrm{Ib},-7.5 \mathrm{log} \mathrm{mol} / \mathrm{L}$ for subgroups Ia and Id, and $-7 \log \mathrm{mol} / \mathrm{L}$ for subgroup Ic) to reach a similar contraction force, because the arteries in subgroups $\mathrm{Ib}$ and Id were already contracted with $20-\mathrm{mmol} / \mathrm{L}$ potassium ion. Subsequently, concentration-relaxation curves were established for bradykinin $(-10$ to $-6.5 \log \mathrm{mol} / \mathrm{L})$ in the presence of indomethacin, L-NNA, and oxyhemoglobin. This relaxation was the EDHFmediated relaxation, because the production of both nitric oxide and $\mathrm{PGI}_{2}$ were inhibited. ${ }^{7}$ 
Group II ( $\mathrm{N}=6$ IN EACH SUBGROUP). Effect of potassium ion $(20 \mathrm{mmol} / \mathrm{L})$ or magnesium ion $(16 \mathrm{mmol} / \mathrm{L})$ on sodium nitroprusside-induced relaxation in microarteries.

Four rings taken from the same artery (subgroups IIa-IId) were incubated with different solutions as in group I. After 1 hour, sodium nitroprusside (SNP, -9 to $-4 \log \mathrm{mol} / \mathrm{L}$ ) was cumulatively applied to induce relaxation in the arteries previously contracted with $\mathrm{U}_{46619}(-8.4$ to $-7 \log \mathrm{mol} / \mathrm{L}$, see group I).

GROUP III ( $\mathrm{N}=8$ IN EACH SUBGROUP). Effect of potassium ion (20 $\mathrm{mmol} / \mathrm{L})$ or magnesium ion $(16 \mathrm{mmol} / \mathrm{L})$ on endotheliumderived hyperpolarizing factor-mediated relaxation in microarteries after washout.

The protocol was similar to that in group I. Four rings taken from the same artery were allocated into four subgroups. The arterial rings were incubated with four different solutions for 1 hour at $37^{\circ} \mathrm{C}$ : subgroup IIIa, Krebs solution as a control; subgroup IIIb, 20-mmol/L potassium ion; subgroup IIIc, 16-mmol/L magnesium ion; and subgroup IIId, 20-mmol/L potassium ion plus 16-mmol/L magnesium ion. In these high-potassium ion or highmagnesium ion solutions, sodium was replaced with the equivalent potassium or magnesium form as described previously. One hour later, the solutions were replaced with the normal Krebs solution, and inhibitors for $\mathrm{PGI}_{2}$ and nitric oxide were added into the chamber. The washout time was 45 minutes. The arteries were contracted with $\mathrm{U}_{46619}(-8.0 \mathrm{log} \mathrm{mol} / \mathrm{L})$. Subsequently, concentration-relaxation curves were then established for bradykinin $(-10$ to $-6.5 \log \mathrm{mol} / \mathrm{L})$ in the presence of indomethacin, L-NNA, and oxyhemoglobin.

In another group of experiments, arterial rings $(n=8)$ were denuded of endothelium mechanically to examine the endothelium dependence of the bradykinin-induced relaxation.

\section{Electrophysiological Studies (Cellular Membrane Potential Measurement)}

Porcine epicardial coronary arteries were dissected out, and a segment (3-4 mm) was carefully slit along the longitudinal axis. The strips were pinned down by stainless steel pins, inner side upward, on the bottom of a 2-mL organ bath. The strip of the coronary artery was superfused with Krebs solution at the rate of $2 \mathrm{~mL} / \mathrm{min}$, aerated with mixture of $95 \%$ oxygen and $5 \%$ carbon dioxide at $37^{\circ} \mathrm{C}$. After 60 minutes of equilibrium, a glass microelectrode filled with $3-\mathrm{mol} / \mathrm{L}$ potassium chloride (tip resistance 40-80 M $\Omega$ ) was inserted into a smooth muscle cell from the endothelial side.6,7,9 The electrical signals were amplified by means of a microelectrode amplifier electrometer (ELECTRO 705; World Precision Instruments, Inc, Sarasota, Fla). The output signals were displayed on an oscilloscope (2120 B; World Precision Instruments) and recorded by a computer that installed Picoscope program (Pico Technology Limited, Hardwick, United Kingdom). The criteria of impaling cells were a sudden negative change in voltage followed by a stable negative voltage for more than 1 minute as well as an instantaneous return to the previous voltage level on dislodgment of the microelectrode. 6,7,9,16-18

Protocols. After equilibrium for 60 minutes, a microelectrode was inserted into the smooth muscle cell and the baseline (resting) membrane potential was recorded. In the presence of indomethacin ( $7 \mu \mathrm{mol} / \mathrm{L})$ and L-NNA $(300 \mu \mathrm{mol} / \mathrm{L})$ for 30 minutes, concentration-response (hyperpolarization) curves were established for bra- dykinin $(-10$ to $-6.5 \log \mathrm{mol} / \mathrm{L})$ as a control. The vascular strip was washed with normal Krebs solution for 30 minutes to restore the baseline (resting) membrane potential and then superfused with one of the three modified Krebs solutions containing 20-mmol/L potassium ion, $16-\mathrm{mmol} / \mathrm{L}$ magnesium ion, or $20-\mathrm{mmol} / \mathrm{L}$ potassium ion plus 16-mmol/L magnesium ion (final concentration). In these solutions, sodium was replaced with the equivalent potassium or magnesium form as described previously to maintain the final osmolarity of the solution. The protocols were as follows: subgroup IVa, superfusion with Krebs solution containing 20$\mathrm{mmol} / \mathrm{L}$ potassium ion for 1 hour; subgroup IVb, superfusion with Krebs solution containing 16-mmol/L magnesium ion for 1 hour; and subgroup IVc, superfusion with Krebs solution containing 20-mmol/L potassium ion and 16-mmol/L magnesium ion for 1 hour.

The vessel was then washed within 30 minutes, and the concentration-response (hyperpolarization) curve for bradykinin was established with the presence of indomethacin $(7 \mu \mathrm{mol} / \mathrm{L})$ and L-NNA $(300 \mu \mathrm{mol} / \mathrm{L})$. Another group of coronary arterial strips were used as the time control for the bradykinin-induced hyperpolarization.

In separate experiments, coronary arteries $(n=6)$ were denuded of endothelium mechanically to examine the endothelium dependence of the bradykinin-induced hyperpolarization.

\section{Data Analysis}

Relaxation was expressed as the percentage decrease in isometric force induced by $\mathrm{U}_{46619}$. The effective concentration of bradykinin that caused $50 \%$ of maximal relaxation was defined as the $\mathrm{EC}_{50}$. The $\mathrm{EC}_{50}$ was determined from each concentration-relaxation curve by a logistic, curve-fitting equation: $\mathrm{E}=\mathrm{MA}^{\mathrm{P}} /\left(\mathrm{A}^{\mathrm{P}}+\mathrm{K}^{\mathrm{P}}\right)$, where $E$ is response, $M$ is maximal relaxation, $A$ is concentration, $K$ is $\mathrm{EC}_{50}$, and $P$ is the slope parameter. From this fitted equation, the mean $( \pm \mathrm{SEM}) \mathrm{EC}_{50}$ was calculated for each group.

\section{Statistical Analysis}

Data were expressed as mean \pm SEM and were analyzed with analysis of variance (ANOVA) followed by the Scheffé $F$ test or $t$ test as appropriate.

\section{Drugs}

Drugs used and their sources were as follows: bradykinin, 1-NNA, and indomethacin, Sigma Chemical Co (St Louis, Mo); and $\mathrm{U}_{46619}$, Cayman Chemical (Ann Arbor, Mich). L-NNA (dissolved in distilled water) and indomethacin (dissolved in ethanol) were stored at $4^{\circ} \mathrm{C}$. The solution of $\mathrm{U}_{46619}$ was held frozen until required.

\section{Results}

\section{Relaxation Studies}

Arterial tone during incubation. The arterial tone values during the incubation with different ions showed marked differences. Compared with a slight increase in tone in the control preparation, $20-\mathrm{mmol} / \mathrm{L}$ potassium ion caused a significant contraction $(10.4 \pm 1.1 \mathrm{mN}$ vs $1.0 \pm 0.2 \mathrm{mN}$, $95 \%$ confidence interval $[\mathrm{CI}]-11.9$ to $-6.9 \mathrm{mN}, P<$ $.001)$, whereas incubation with magnesium ion slightly reduced the tone $(-0.5 \pm 0.1 \mathrm{mN}$ vs $1.0 \pm 0.2 \mathrm{mN}, 95 \% \mathrm{CI}$ 


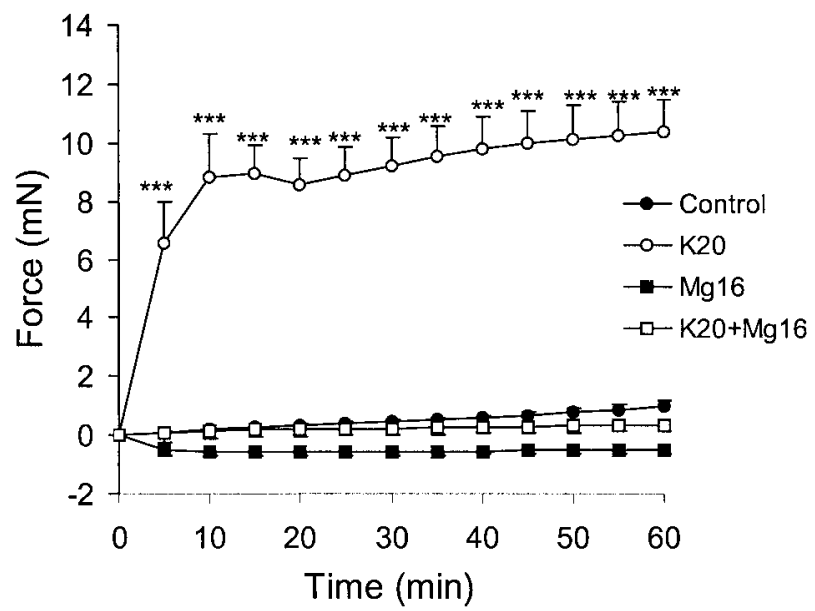

Figure 1. Change in resting force in porcine coronary microarteries during incubation with Krebs solution (control, subgroup la, filled circles) or solution containing $20-\mathrm{mmol} / \mathrm{L}$ potassium ion (subgroup Ib, open circles), 16-mmol/L magnesium ion (subgroup Ic, filled squares), or $20-\mathrm{mmol} / \mathrm{L}$ potassium ion plus $16 \mathrm{mmol} / \mathrm{L}$ magnesium ion (subgroup Id, open squares). Four rings taken from same microartery were allocated in four chambers of myograph, $\mathrm{n}=\mathbf{8}$ in each group. Triple asterisk indicates $\boldsymbol{P}<.001$ vs Krebs solution by ANOVA and Scheffé $\boldsymbol{F}$ test.

-1.0 to $4.0 \mathrm{mN}, P=.378$ ). The effect on the tone of $20-\mathrm{mmol} / \mathrm{L}$ potassium ion plus $16-\mathrm{mmol} / \mathrm{L}$ magnesium ion was between the control value and the value achieved with 16-mmol/L magnesium ion alone (Figure 1).

Comparison of precontraction. In the group I arteries, magnesium ion markedly depressed the contractile response to $\mathrm{U}_{46619}$, whereas potassium ion caused a significant contraction before addition of $\mathrm{U}_{46619}$. To make the subsequent relaxations comparable, we intended to induce a comparable precontraction by using different concentrations of $\mathrm{U}_{46619}$, ranging from $-8.4 \log \mathrm{mol} / \mathrm{L}$ to $-7 \log \mathrm{mol} / \mathrm{L}$. However, there was still a difference among the 4 subgroups of group I ( $P<.001$ by ANOVA), although the differences between the control subgroup (subgroup Ia) and the other subgroups did not reach statistical significance according to the post hoc test Scheffé $F$ test (Figure 2, A). Further, in subgroup $\mathrm{Ib}$ the contraction induced by potassium ion and then $\mathrm{U}_{46619}$ was higher than that in subgroups Ic $(18.0 \pm 2.2$ $\mathrm{mN}$ vs $6.0 \pm 1.0 \mathrm{mN}, 95 \%$ CI $5.1-18.9 \mathrm{mN}, P<.001$ by Scheffé $F$ test $)$ and Id $(18.0 \pm 2.2 \mathrm{mN}$ vs $10.2 \pm 1.4 \mathrm{mN}$, $95 \%$ CI 1.0-14.7 mN, $P=.021$ by Scheffé F test; Figure 2, $A)$. However, this difference disappeared when the incubated solution was washed out (group II, $P=.733$; Figure $2, B)$.

Effects of 20-mmol/L potassium ion, 16-mmol/L magnesium ion, or both on bradykinin-induced relaxation (group I). In group I, exposure to $20-\mathrm{mmol} / \mathrm{L}$ potassium ion (subgroup Ib) greatly reduced the bradykinin-induced
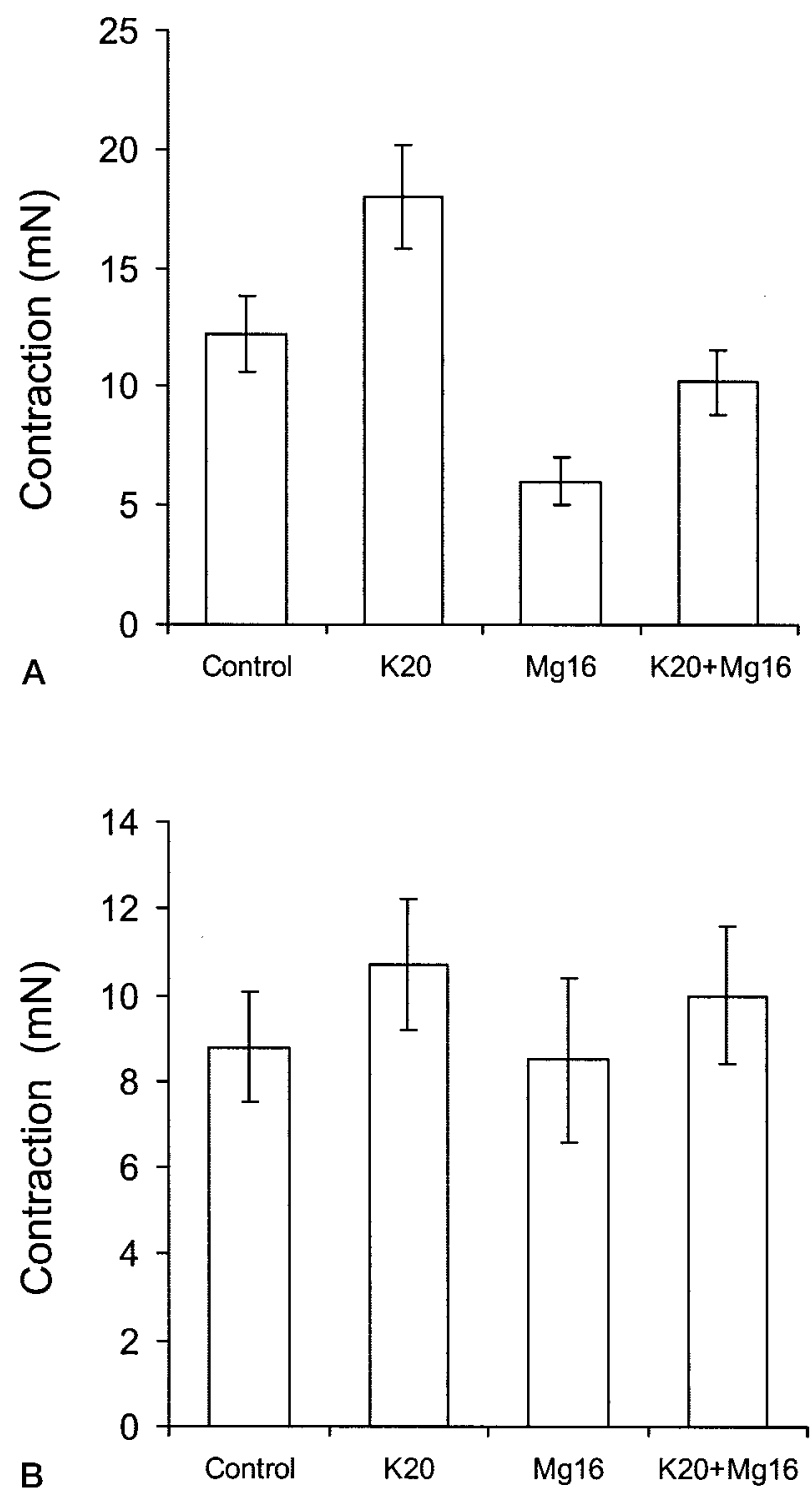

Figure 2. Mean contraction force response to $U_{46619}$ (range -8 to $-7 \log \mathrm{mol} / \mathrm{L}$, see Methods section) after exposure to Krebs solution (control, subgroup la) or solution containing $20-\mathrm{mmol} / \mathrm{L}$ potassium ion (subgroup lb, K20), 16- $\mathrm{mmol} / \mathrm{L}$ magnesium ion (subgroup Ic, Mg16), or potassium ion plus magnesium ion (subgroup Id, K20+Mg16) for 1 hour in groups I (A) and III (B). Four rings taken from same microartery were allocated in four chambers of myograph, $n=8$ in each group. $A, P<.001$ among 4 subgroups by ANOVA, but $\boldsymbol{P}>.05$ for subgroups Ib, Ic, and Id compared with Krebs solution (control subgroup) by ANOVA and Scheffé $F$ test. B, $P>.05$ among 4 subgroups.

EDHF-mediated relaxation $(35.0 \% \pm 4.9 \%$ vs $86.0 \% \pm$ $5.3 \%, 95 \%$ CI $31.7 \%-70.2 \%, P<.001)$. Magnesium ion (subgroup Ic) slightly reduced this relaxation, but without statistical significance $(P=.243)$. Most important, the addition of magnesium ion to a hyperkalemic solution (sub- 
TABLE 1. Maximal relaxation and $\mathrm{EC}_{50}$ values for bradykinin in the presence of indomethacin (7 $\left.\mu \mathrm{mol} / \mathrm{L}\right)$, L-NNA (300 $\mu \mathrm{mol} / \mathrm{L}$ ), and oxyhemoglobin $(20 \mu \mathrm{mol} / \mathrm{L}$ ) in porcine coronary microarteries exposed for 1 hour to Krebs solution (control, subgroup la), 20-mmol/L potassium ion (subgroup lb), 16- $\mathrm{mmol} / \mathrm{L}$ magnesium ion (subgroup Ic), or 20-mmol/L potassium ion plus 16-mmol/L magnesium ion (subgroup Id)

\begin{tabular}{|c|c|c|c|c|}
\hline & Maximal relaxation (\%) & $P$ value & $\mathrm{EC}_{50}(-\log \mathrm{mol} / \mathrm{L})$ & $P$ value \\
\hline Subgroup la (control) & $86.0 \pm 5.3$ & & $-7.85 \pm 0.17$ & \\
\hline Subgroup Ib & $35.0 \pm 4.9$ & $<.001$ & $-7.36 \pm 0.69 *$ & .529 \\
\hline Subgroup Ic & $72.4 \pm 4.0$ & .243 & $-7.70 \pm 0.24$ & .630 \\
\hline Subgroup Id & $51.9 \pm 4.0$ & $<.001$ & $-7.22 \pm 0.24^{*}$ & .052 \\
\hline
\end{tabular}

$P$ values are versus control subgroup according to unpaired $t$ test.

*In 3 of 8 rings, the $\mathrm{EC}_{50}$ was so high that could not be calculated from the curve-fitting equation (see Methods section). This actually implies a significant difference of the $\mathrm{EC}_{50}$ from the control value.

group Id) led to significant recovery of the reduction of the relaxation induced by potassium ion alone $(51.9 \% \pm 4.0 \%$ vs $35.0 \% \pm 4.9 \%, 95 \% \mathrm{CI}-30.4 \%$ to $-3.4 \%, P=.017$; Table 1 and Figure 3, A).

In group III, the influence of $20-\mathrm{mmol} / \mathrm{L}$ potassium ion (subgroup IIIb) on the bradykinin-induced EDHF-mediated relaxation was reduced to minimum by washout for 45 minutes, although there was still a slight reduction of the relaxation in subgroup IIIb relative to the control subgroup (subgroup IIIa, $73.8 \% \pm 8.9 \%$ vs $87.1 \% \pm 7.0 \%, 95 \% \mathrm{CI}$ $-11.1 \%$ to $37.5 \%, P=.2$; Figure 4 ).

With respect to $\mathrm{EC}_{50}$, after incubation with $20-\mathrm{mmol} / \mathrm{L}$ potassium ion, the significantly reduced relaxation in 3 of 8 arteries caused an $\mathrm{EC}_{50}$ so high that it could not be calculated from the curve-fitting equation (see Methods section). Similarly, the $\mathrm{EC}_{50}$ could not be calculated in 3 rings incubated with $20-\mathrm{mmol} / \mathrm{L}$ potassium ion plus $16-\mathrm{mmol} / \mathrm{L}$ magnesium ion, and in the remaining 5 rings the $\mathrm{EC}_{50}$ was slightly higher than that in the control subgroup $(P=.052$ vs by unpaired $t$ test; Table 1$)$. These results imply that incubation with $20-\mathrm{mmol} / \mathrm{L}$ potassium ion either with or without magnesium ion significantly decreased the sensitivity of the artery to bradykinin (increased $\mathrm{EC}_{50}$ ). In group III, there were no differences between the control subgroup and other subgroups with respect to the $\mathrm{EC}_{50}$.

In the 8 arteries with the endothelium denuded, the bradykinin-induced relaxation was abolished.

Effects of 20-mmol/L potassium ion, 16- $\mathrm{mmol} / \mathrm{L} \mathrm{mag-}$ nesium ion, or both on sodium nitroprusside-induced relaxation (group II). SNP caused marked vasorelaxation in a concentration-dependent manner, and full relaxation $(100 \%)$ occurred at $-4 \log \mathrm{mol} / \mathrm{L}$. Incubation with either 20-mmol/L potassium ion (subgroup IIb), 16-mmol/L magnesium ion (subgroup IIc), or $20-\mathrm{mmol} / \mathrm{L}$ potassium ion plus 16-mmol/L magnesium ion (subgroup IId) did not alter the SNP-induced relaxation $(97.9 \% \pm 0.9 \%$ in subgroup $\mathrm{IIb}, 100 \% \pm 0 \%$ in subgroup IIc, and $99.2 \% \pm 0.8 \%$ in subgroup IId, $P>.05$; Figure $3, B$ ). In addition, there were no differences in $\mathrm{EC}_{50}$ among these 4 subgroups.

\section{Electrophysiologic Studies}

Membrane potential during incubation. During incubation, the membrane potential was significantly depolarized by $20-\mathrm{mmol} / \mathrm{L}$ potassium ion $(-39.7 \pm 1.5 \mathrm{vs}-60.1 \pm 0.5$ $\mathrm{mV}, P<.001)$. In contrast, incubation with $16-\mathrm{mmol} / \mathrm{L}$ magnesium ion hyperpolarized the membrane potential from $-60.4 \pm 1.5$ to $-63.3 \pm 1.6 \mathrm{mV}(P=.001)$. Interestingly, incubation with $20-\mathrm{mmol} / \mathrm{L}$ potassium ion plus 16- $\mathrm{mmol} / \mathrm{L}$ magnesium ion partially depolarized the membrane potential $(-49.0 \pm 1.4 \mathrm{vs}-60.1 \pm 1.5 \mathrm{mV}, P<$ .001 ), and the magnitude of the depolarization was significantly less than that in the subgroup IVa $(P<.01$, Figure 5$)$. During the washout period, the membrane potential remained slightly higher (in subgroup IVa, Figure 6, A) or returned to the previous level (in subgroups IVb and IVc, Figure 6, $B$ and $C$ ).

Bradykinin-induced hyperpolarization. Bradykinin (-10 to $-6.5 \log \mathrm{mol} / \mathrm{L}$ ) induced a concentration-dependent hyperpolarization in the porcine coronary artery. After superfusion with $20-\mathrm{mmol} / \mathrm{L}$ potassium ion for 1 hour (subgroup IVa), the bradykinin-induced hyperpolarization was reduced (Figure 6, A). The maximal change was from $-72.0 \pm 1.5 \mathrm{mV}$ to $-61.7 \pm 1.5 \mathrm{mV}(\mathrm{n}=7, P<.01)$. In contrast, superfusion with magnesium ion (subgroup IVb) did not alter the hyperpolarization (Figure $6, B$ ). When the superfusion was $20-\mathrm{mmol} / \mathrm{L}$ potassium ion plus $16-\mathrm{mmol} / \mathrm{L}$ magnesium ion (subgroup IVc), the hyperpolarization was significantly reduced relative to the control value $(-68.0 \pm$ $2.5 \mathrm{mV}$ vs $-72.5 \pm 1.5 \mathrm{mV}, \mathrm{n}=6, P<.05$; Figure $6, C$ ). However, compared with superfusion with potassium ion 20 $\mathrm{mmol} / \mathrm{L}$ alone, the change of the membrane potential was significantly recovered $(10.0 \pm 1.0$ vs. $3.3 \pm 0.8 \mathrm{mV}, \mathrm{n}=$ $7, \mathrm{P}<.01$ ) (Figure $6, D$ ). Figure $5, D$, also shows the comparison of the magnitude of the change of membrane potential in response to bradykinin among the subgroups of group IV. Potassium ion greatly reduced the magnitude of bradykinin-induced hyperpolarization of the membrane potential, whereas magnesium ion did not. In the 8 arteries 

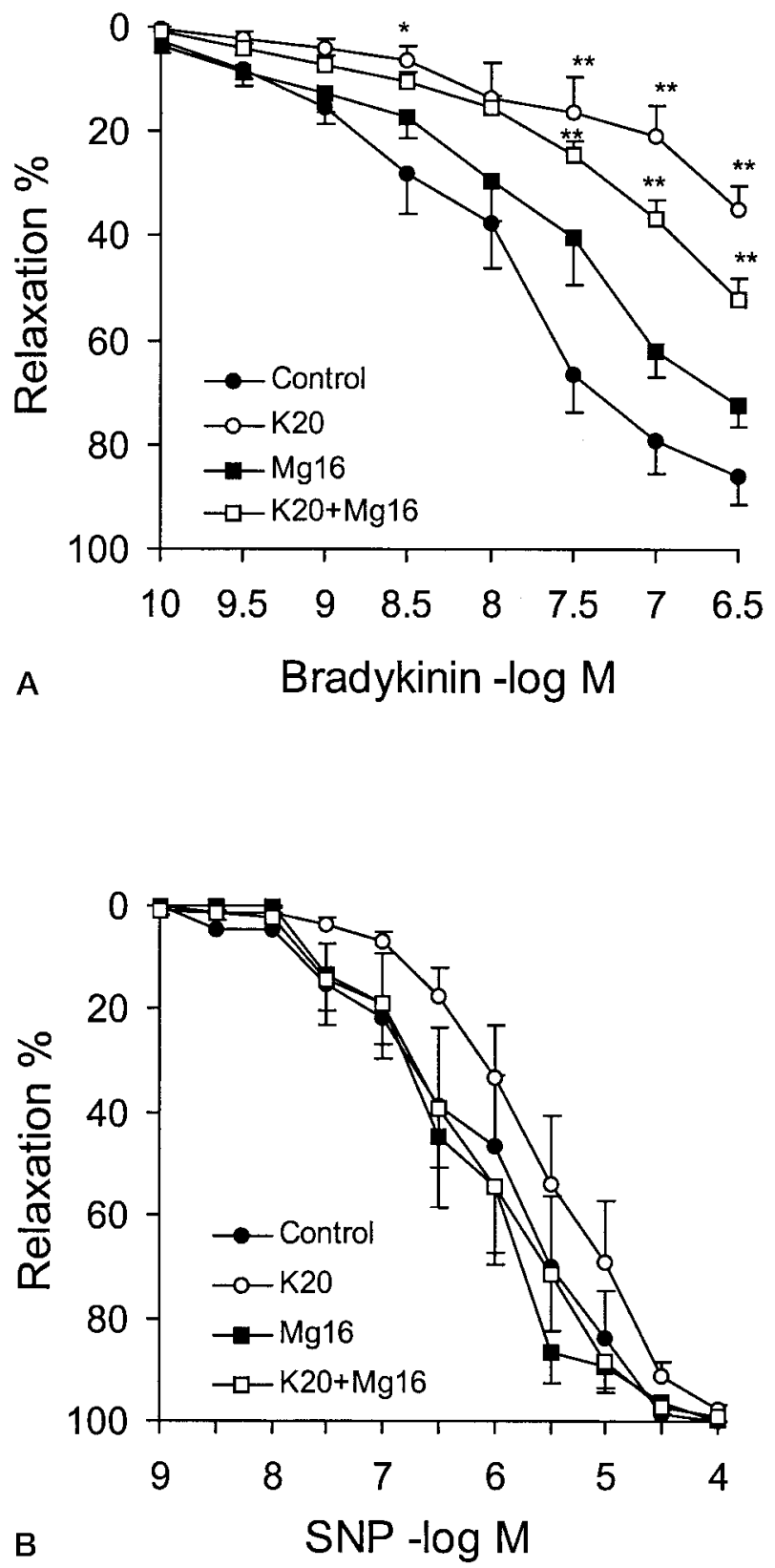

Figure 3. Concentration-relaxation curves for bradykinin ( $A$, group I) and SNP (B, group II) in $U_{46619}$-precontracted porcine coronary microarteries. Bradykinin-induced relaxation was performed with presence of indomethacin ( $7 \mu \mathrm{mol} / \mathrm{L}$ ), I-NNA (300 $\mu \mathrm{mol} / \mathrm{L}$ ), and oxyhemoglobin $(20 \mu \mathrm{mol} / \mathrm{L}$ ) after exposure to following solutions for 1 hour: subgroup la or lla (control, filled circles), Krebs solution; subgroup Ib or Ilb (open circles), solution containing 20-mmol/L potassium ion; subgroup Ic or Ilc (filled squares), solution containing 16-mmol/L magnesium ion; and subgroup Id or Ild (open squares), solution containing $20-\mathrm{mmol} / \mathrm{L}$ potassium ion plus 16-mmol/L magnesium ion. Four rings taken from same microartery were allocated in four chambers of myograph; $\mathbf{n}=\mathbf{8}$ in each subgroup. Asterisk indicates $\boldsymbol{P}<.05$ compared with control subgroup by ANOVA and Scheffé $F$ test; double asterisk indicates $P<.01$.

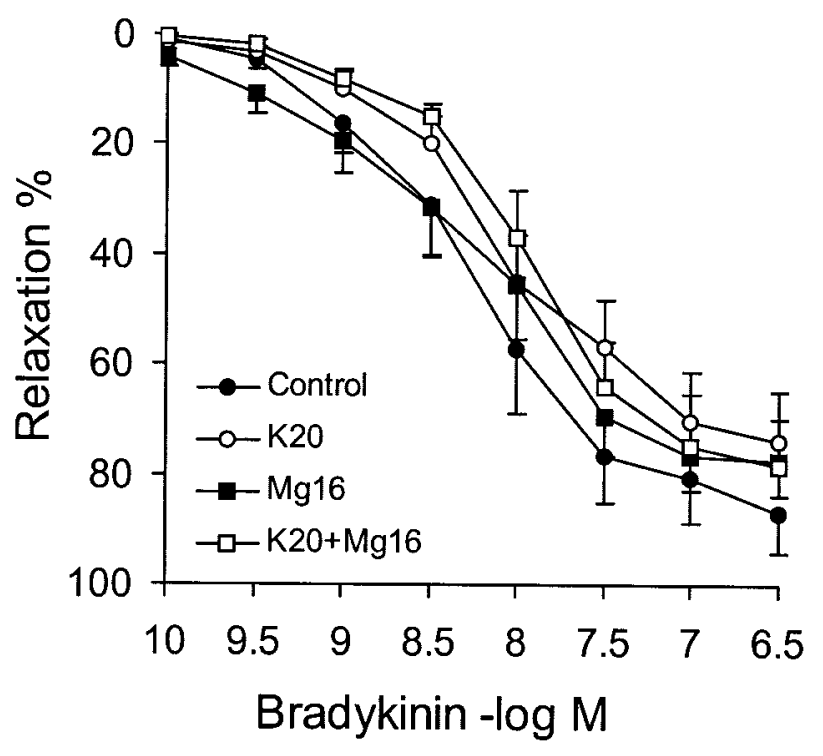

Figure 4. Concentration-relaxation curves for bradykinin (group III) in $\mathbf{U}_{46619}$-precontracted porcine coronary microarteries with presence of indomethacin (7 $\mu \mathrm{mol} / \mathrm{L}), \mathrm{I}-\mathrm{NNA}$ (300 $\mu \mathrm{mol} / \mathrm{L})$, and oxyhemoglobin $(20 \mu \mathrm{mol} / \mathrm{L}$ ) after exposure to following solutions for 1 hour followed by 45-minute washout: subgroup Illa (control, filled circles), Krebs solution; subgroup IIlb (open circles), solution containing $20-\mathrm{mmol} / \mathrm{L}$ potassium ion; subgroup IIIc (filled squares), solution containing 16- $\mathrm{mmol} / \mathrm{L}$ magnesium ion; and subgroup Illd (open squares), solution containing $20-\mathrm{mmol} / \mathrm{L}$ potassium ion plus 16-mmol/L magnesium ion. Four rings taken from same microartery were allocated in four chambers of myograph; $\mathrm{n}=\mathbf{8}$ in each subgroup.

with the endothelium denuded, the bradykinin-induced hyperpolarization was abolished.

\section{Discussion}

This study has demonstrated for the first time that magnesium ion alone preserves EDHF-mediated relaxation and hyperpolarization in porcine coronary arteries, that magnesium ion added to hyperkalemic cardioplegic solutions restores EDHF-mediated relaxation and hyperpolarization, and that the mechanism of the protective effect of magnesium ion is related to the preservation of the membrane hyperpolarization and the reversal of the potassium ioninduced depolarization of smooth muscle cells.

\section{Coronary Tone During Incubation With Magnesium Ion}

In this study, the coronary microarterial tone increased when the vessel was incubated with $20-\mathrm{mmol} / \mathrm{L}$ potassium ion, a well-known phenomenon. We previously demonstrated that the coronary tone remains almost without change when the artery is incubated with St Thomas Hospital cardioplegic solution, which also contains $20-\mathrm{mmol} / \mathrm{L}$ potassium ion. The difference between the effects of these 
two solutions is obviously related to other components in the St Thomas Hospital solution, and we therefore became interested in investigating the effects of another main cation contained in St Thomas Hospital cardioplegic solution, 16$\mathrm{mmol} / \mathrm{L}$ magnesium ion. The effects of magnesium ion on the vascular tone may be 2-fold, on the resting force and on contracted vessels.

The inhibitory effect of magnesium ion on the potassium ion-induced increase in tone is clearly shown in Figure 1. Compared with the marked increase in tone induced by $20-\mathrm{mmol} / \mathrm{L}$ potassium ion, addition of $16-\mathrm{mmol} / \mathrm{L}$ magnesium ion completely inhibited the potassium-induced contraction. When the coronary artery was incubated with 16$\mathrm{mmol} / \mathrm{L}$ magnesium ion alone, the tone was slightly reduced relative to the control value. Thus in the coronary arteries in both resting and contracted states, the effect of 16-mmol-L magnesium ion is to reduce the tone.

It has been reported that the effects of magnesium ion on the vasculature involve a few mechanisms. Nakajima and associates $^{19}$ reported that extracellular magnesium ion inhibits receptor-mediated nonselective cation current, which may contribute to the relaxation effects in vascular smooth muscle cells. Skajaa and colleagues ${ }^{20}$ demonstrated that magnesium ion inhibits the vascular response to several vasoconstrictors, such as potassium ion and prostaglandin $\mathrm{F}_{2 \alpha}$, through affecting transmembrane calcium influx and interfering with intracellular calcium effects. ${ }^{20}$ Further, it has been suggested that extracellular magnesium ion at low concentrations $(0.1-6 \mathrm{nmol} / \mathrm{L})$ can promote relaxation by endothelium-derived relaxing factor and nitric oxide ${ }^{21}$ and by cyclo-oxygenase-dependent mechanisms, such as the production of prostacyclin. ${ }^{22}$ Because the concentration of magnesium ion was as high as $16 \mathrm{mmol} / \mathrm{L}$, we believe that the mechanism of its inhibitory effect on contraction was related to the direct action on the vascular smooth muscle, as mentioned previously. ${ }^{19,20}$

The Membrane Potential of the Smooth Muscle in the Coronary Artery During Incubation with Magnesium Ion

In the resting state, in contrast to potassium ion, magnesium ion alone at the concentration in St Thomas Hospital cardioplegic solution (16 mmol/L) significantly decreased the membrane potential (hyperpolarization; Figure 4). Further, the addition of magnesium ion to hyperkalemic solutions reduced the depolarization caused by potassium ion alone $(P=.008)$, although the membrane potential was still partially depolarized (Figure 4). These experiments clearly demonstrate that the effect of magnesium ion is to reduce the membrane potential either in the resting state or when the membrane is depolarized. Combined with the findings in the force recording during incubation that magnesium ion, either alone or added to the potassium ion solution, slightly reduced the resting force (Figure 1), the results clearly show that the previously found reduction

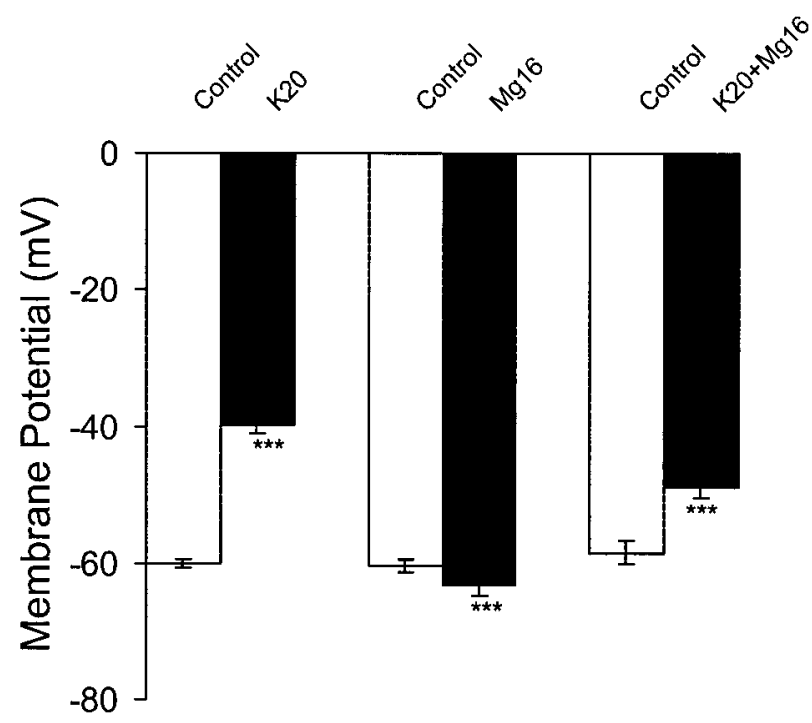

Figure 5. Mean membrane potential of smooth muscle cells of porcine coronary arteries in presence of indomethacin $(7 \mu \mathrm{mol} / \mathrm{L})$ and I-NNA (300 $\mu \mathrm{mol} / \mathrm{L})$ after superfusion for 1 hour with solution containing $20-\mathrm{mmol} / \mathrm{L}$ potassium ion (subgroup $\mathrm{IVa}, \mathrm{n}=7, \mathrm{K2O}$ ), solution containing 16-mmol/L magnesium ion (subgroup IVb, $\mathbf{n}=$ 6 , Mg16), or solution containing $20-\mathrm{mmol} / \mathrm{L}$ potassium ion plus 16-mmol/L magnesium ion (subgroup IVc, $\mathrm{n}=6, \mathrm{~K} 20+M g 16$ ). Triple asterisk indicates $\boldsymbol{P}<.001$ versus control subgroup (before superfusion) by paired $t$ test.

of resting force during incubation with St Thomas Hospital cardioplegic solution ${ }^{15}$ is most likely due to the magnesium ion contained in this solution. In addition, these experiments demonstrate that the mechanism of the reduced tone induced by magnesium ion is due to its relaxation-linked membrane hyperpolarization of the coronary smooth muscle cell.

\section{Effect of magnesium ion on $\mathrm{U}_{46619}$-Induced Contraction}

For similar reasons to those mentioned previously, the contraction induced by $\mathrm{U}_{46619}$ was significantly reduced in the magnesium ion-treated arteries. Even when the dose of $\mathrm{U}_{46619}$ was increased in an attempt to reach a similar extent of contraction for the relaxation studies with bradykinin, the contraction response to $\mathrm{U}_{46619}$ was still less than that in other groups. This effect, however, almost disappeared after washout for 45 minutes.

Effects and Mechanisms of Potassium Ion and Magnesium Ion Action on Endothelium-Derived Hyperpolarizing Factor-Related Relaxation and Hyperpolarization

Effect of potassium ion on endothelium-derived hyperpolarizing factor-related relaxation and hyperpolarization. After incubation with 20-mmol/L potassium ion for 1 hour, the EDHF-mediated relaxation and hyperpolarization in- 

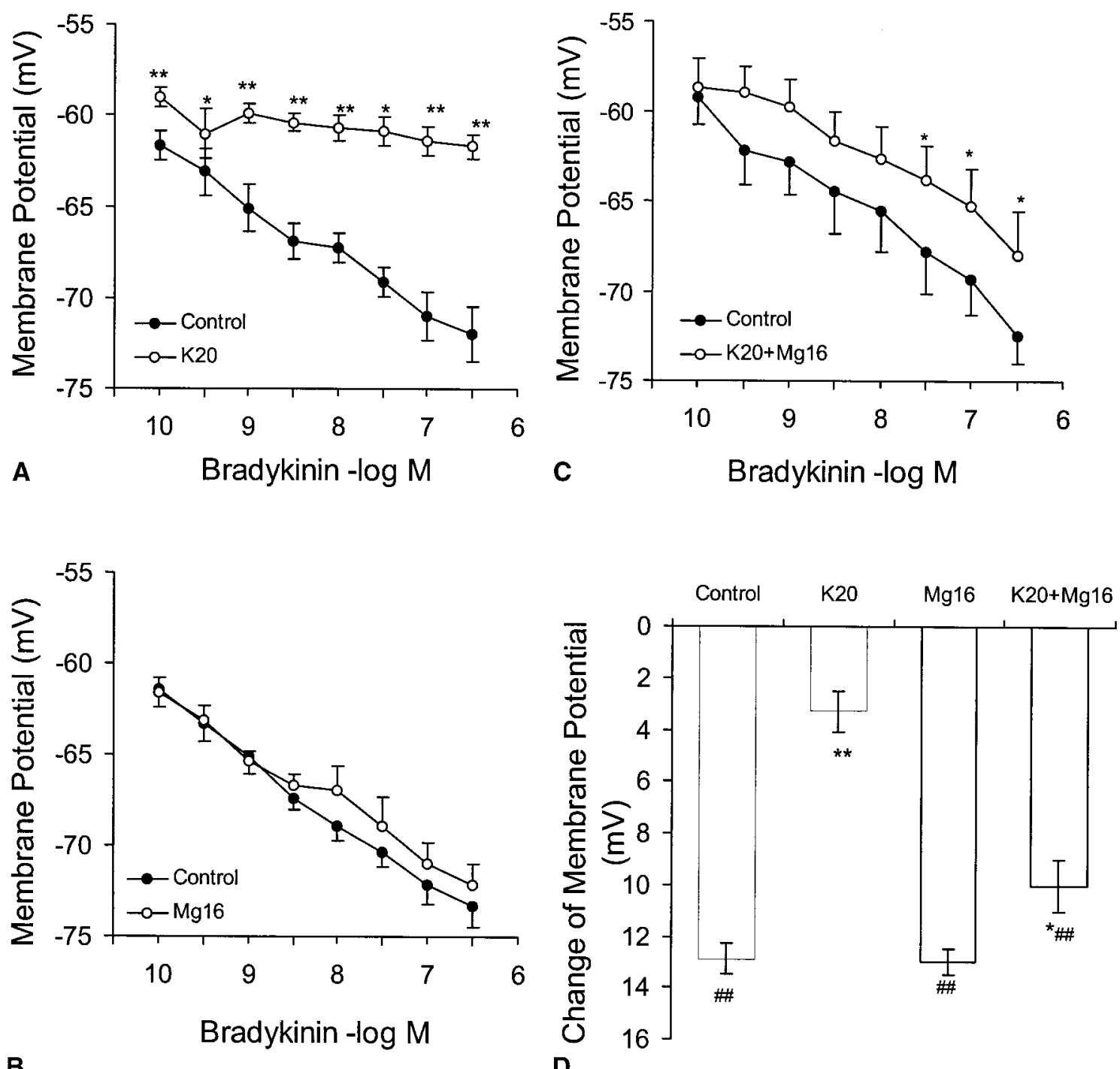

Figure 6. Membrane potential measurement of smooth muscle cells of porcine coronary arteries. Concentrationresponse (membrane potential) curves for bradykinin (A-C) in presence of indomethacin (7 $\mu \mathrm{mol} / \mathrm{L}$ ) and I-NNA (300 $\mu \mathrm{mol} / \mathrm{L}$ ) after superfusion for 1 hour. A, Superfusion with solution containing 20-mmol/L potassium ion (subgroup IVa, $\mathbf{n}=7$, open circles). B, Superfusion with solution containing 16-mmol/L magnesium ion (subgroup IVb, $n=$ 6, open circles). C, Superfusion with solution containing $20-\mathrm{mmol} / \mathrm{L}$ potassium ion plus $16 \mathrm{mmol} / \mathrm{magnesium}$ ion (subgroup IVc, $\mathrm{n}=6$, open circles). D, Change of membrane potential to bradykinin ( $-6.5 \log \mathrm{mol} / \mathrm{L}$ ). Asterisk indicates $\boldsymbol{P}<.05$ vs control subgroup (before superfusion) by paired $\boldsymbol{t}$ test; double asterisk indicates $\boldsymbol{P}<.01$; double pound sign indicates $p<.01$ vs 20 -mmol/L potassium by unpaired $t$ test.

duced by bradykinin were significantly reduced. These results are consistent with our previous studies, which demonstrated that EDHF-mediated response was impaired by hyperkalemia. ${ }^{6,8-10}$ The mechanism of the impairment may involve prolonged membrane depolarization and altered activity of the calcium-activated potassium channels. ${ }^{6,8}$ The effect of 20-mmol/L potassium ion on the hyperpolarization induced by bradykinin was demonstrated in this study. The membrane potential was greatly increased (depolarization) in the coronary artery and the bradykinin-induced hyperpolarization was also greatly reduced (Figure 5). The change in this relaxation-linked hyperpolarization further reveals the mechanism of the hyperkalemia-induced reduction of the EDHF-mediated function.

Effect of magnesium ion on endothelium-derived hyperpolarizing factor-related relaxation and hyperpolarization. In contrast, incubation with magnesium ion did not significantly alter either the relaxation or the hyperpolariza- 
tion induced by bradykinin (Figures 3 and $5, B$ ). These results clearly show that the addition of magnesium ion in a physiologic solution completely preserves EDHF-mediated endothelial function. This is already a favorable effect. More important, addition of magnesium ion to a hyperkalemic cardioplegic solution can reduce the impairment of the EDHF-mediated function. When the artery was incubated with potassium ion plus magnesium ion, the bradykinininduced EDHF-mediated relaxation was partially preserved relative to that in the arteries incubated with potassium ion alone (Figure 3, A). This partial recovery in the EDHFmediated endothelial function was due to the protective effect of magnesium ion on the EDHF function, because the membrane hyperpolarization induced by bradykinin after incubation with potassium ion plus magnesium ion was significantly more than that in arteries incubated with potassium ion alone $(P<.01$, Figure $6, A, C$, and $D)$. As previously demonstrated, hyperkalemia impairs EDHFmediated relaxation by depolarizing the membrane and inhibiting the calcium-activated potassium channels. ${ }^{6,8-10}$ Taken together, the effects of potassium ion and magnesium ion on the membrane potential result in a favorable effect of magnesium ion when added to the hyperkalemic solution. Figure 6 depicts the effects of both potassium ion and magnesium ion on the membrane potential of the coronary smooth muscle cell regarding the EDHF-mediated endothelial function and shows the possible mechanisms of action.

This study therefore demonstrated that the restoration of the relaxation-linked hyperpolarization of the membrane potential of coronary smooth muscle cells by magnesium ion is the mechanism of the protective effect of the EDHFmediated relaxation by magnesium ion. This finding further supports the use of magnesium ion in cardioplegic solutions.

\section{Limitations of the Study}

This study addressed an important consideration in cardioplegic arrest regarding the effect of magnesium ion. However, the study was an in vitro experimental investigation. The effect of reduced sodium in the experiment (to exclude the effect of changed osmolarity) is unknown. In addition, the overall effect of the alteration of the EDHFmediated relaxation after cardioplegic arrest on the coronary flow remains to be studied further.

\section{Clinical Implications}

Magnesium ion has been shown to have a cardioprotective effect against ischemia-reperfusion injury. ${ }^{13,23-27}$ This study demonstrated that magnesium ion alone completely preserves EDHF-mediated endothelial function, and when added to hyperkalemic cardioplegia it allows significant recovery of the EDHF-mediated endothelial function impaired by the high potassium ion concentration. Therefore this study provides strong evidence that supplementation of magnesium ion in hyperkalemic cardioplegia is essential for endothelial protection.

In conclusion, magnesium ion alone preserved EDHFmediated relaxation and hyperpolarization in porcine coronary microarteries in vitro. When added to hyperkalemic cardioplegia, magnesium ion significantly restored the EDHF-mediated endothelial function impaired by hyperkalemia. The mechanism of the protective effect of magnesium ion is related to the preservation of the membrane hyperpolarization and the reversal of the potassium ioninduced depolarization of the smooth muscle cell. Thus this study strongly supports the use of magnesium ion in cardioplegic solutions.

\section{References}

1. Hearse DJ, Braimbridge MV, Jynge P. Protection of the ischemia myocardium: cardioplegia. New York: Raven; 1981.

2. Nilsson FN, Miller VM, Vanhoutte PM, McGregor CG. Methods of cardiac preservation alter the function of the endothelium in porcine coronary arteries. J Thorac Cardiovasc Surg. 1991;102:923-9.

3. Saldanha C, Hearse DJ. Coronary vascular responsiveness to 5hydroxytryptamine before and after infusion of hyperkalemic crystalloid cardioplegic solution in the rat heart: possible evidence of endothelial damage. J Thorac Cardiovasc Surg. 1989;98:783-7.

4. Evora PR, Pearson PJ, Schaff HV. Crystalloid cardioplegia and hypothermia do not impair endothelium-dependent relaxation or damage vascular smooth muscle of epicardial coronary arteries. J Thorac Cardiovasc Surg. 1992;104:1365-74.

5. Feletou M, Vanhoutte PM. Endothelium-dependent hyperpolarization of canine coronary smooth muscle. Br J Pharmacol. 1988;93:515-24.

6. He GW, Yang CQ, Graier WF, Yang JA. Hyperkalemia alters EDHFmediated hyperpolarization and relaxation in coronary arteries. Am J Physiol. 1996;271(2 Pt 2):H760-7.

7. Ge ZD, Zhang XH, Fung PC, He GW. Endothelium-dependent hyperpolarization and relaxation resistance to $\mathrm{N}(\mathrm{G})$-nitro-L-arginine and indomethacin in coronary circulation. Cardiovasc Res. 2000;46:54756.

8. He GW. Hyperkalemia exposure impairs EDHF-mediated endothelial function in the human coronary artery. Ann Thorac Surg. 1997;63: 84-7.

9. He GW, Yang CQ, Yang JA. Depolarizing cardiac arrest and endothelium-derived hyperpolarizing factor-mediated hyperpolarization and relaxation in coronary arteries: the effect and mechanism. $J$ Thorac Cardiovasc Surg. 1997;113:932-41.

10. Ge ZD, He GW. Altered endothelium-derived hyperpolarizing factormediated endothelial function in coronary microarteries by $\mathrm{St}$ Thomas' Hospital solution. J Thorac Cardiovasc Surg. 1999;118:17380.

11. Hearse DJ, Stewart DA, Braimbridge MV. Myocardial protection during ischemia cardiac arrest: the importance of magnesium in cardioplegic infusates. J Thorac Cardiovasc Surg. 1978;75:877-85.

12. Shakerinia T, Ali IM, Sullivan JA. Magnesium in cardioplegia: is it necessary? Can J Surg. 1996;39:397-400.

13. Caputo M, Bryan AJ, Calafiore AM, Suleiman MS, Angelini GD. Intermittent antegrade hyperkalaemic warm blood cardioplegia supplemented with magnesium prevents myocardial substrate derangement in patients undergoing coronary artery bypass surgery. Eur J Cardiothorac Surg. 1998;14:596-601.

14. Tofukuji M, Stamler A, Li J, Franklin A, Wang SY, Hariawala MD, et al. Effects of magnesium cardioplegia on regulation of the porcine coronary circulation. J Surg Res. 1997;69:233-9.

15. He GW, Yang CQ. Vascular tone and contractility during exposure to cardioplegia and hyperkalemic solutions. Vasc Surg. 1995;29:241-72. 
16. Brayden JE. Membrane hyperpolarization is a mechanism of endothelium-dependent cerebral vasodilation. Am J Physiol. 1990;259(3 Pt 2):H668-73.

17. Chen G, Suzuki H, Weston AH. Acetylcholine releases endotheliumderived hyperpolarizing factor and EDRF from rat blood vessels. $\mathrm{Br} J$ Pharmacol. 1988;98:1165-74.

18. Nagao T, Vanhoutte PM. Hyperpolarization contributes to endothelium-dependent relaxations to acetylcholine in femoral veins of rats. Am J Physiol. 1991;261(4 Pt 2):H1034-7.

19. Nakajima T, Iwasawa K, Hazama H, Asano M, Okuda Y, Omata M. Extracellular $\mathrm{Mg} 2+$ inhibits receptor-mediated $\mathrm{Ca}(2+)$-permeable non-selective cation currents in aortic smooth muscle cells. Eur J Pharmacol. 1997;320:81-6.

20. Skajaa K, Forman A, Andersson KE. Effects of magnesium on isolated human fetal and maternal uteroplacental vessels. Acta Physiol Scand. 1990;139:551-9.

21. Laurant $\mathrm{P}$, Berthelot A. Influence of endothelium on $\operatorname{Mg}(2+)$-induced relaxation in noradrenaline-contracted aorta from DOCA-salt hypertensive rat. Eur J Pharmacol. 1994;258:167-72.

22. Laurant $\mathrm{P}$, Berthelot A. Influence of endothelium in the in vitro vasorelaxant effect of magnesium on aortic basal tension in DOCAsalt hypertensive rat. Magnes Res. 1992;5:255-60.

23. Lareau S, Boyle A, Deslauriers R, Keon WJ, Kroft T, Labow RS. Magnesium enhances function of postischaemic human myocardial tissue. Cardiovasc Res. 1993;27:1009-14.

24. Caspi J, Rudis E, Bar I, Safadi T, Saute M. Effect of magnesium on myocardial function after coronary artery bypass grafting. Ann Thorac Surg. 1995;59:942-7.

25. Christensen CW, Rieder MA, Sliverstein EL, Gencheff NE. Magnesium sulfate reduces myocardial infarct size when administered before but not after coronary reperfusion in a canine model. Circulation. 1995;92:2617-21.

26. Ichiba $\mathrm{T}$, Matsuda $\mathrm{N}$, Takemoto $\mathrm{N}$, Ishiguro $\mathrm{S}$, Kuroda H, Mori $\mathrm{T}$. Regulation of intracellular calcium concentrations by calcium and magnesium in cardioplegia solution protects rat neonatal myocytes from simulated ischemia. J Mol Cell Cardiol. 1998;30:1105-14.

27. Kronon MT, Allen BS, Hernan J, Halldorsson AO, Rahman S, Buckberg GD, et al. Superiority of magnesium cardioplegia in neonatal myocardial protection. Ann Thorac Surg. 1999;68:2285-91.

\section{Bound volumes available to subscribers}

Bound volumes of The Journal of Thoracic and Cardiovascular Surgery are available to subscribers (only) for the 2002 issues from the Publisher, at a cost of $\$ 134.00$ for domestic, $\$ 165.85$ for Canadian, and $\$ 155.00$ for international subscribers for Vol 123 (January-June) and Vol 124 (July-December). Shipping charges are included. Each bound volume contains a subject and author index and all advertising is removed. The binding is durable buckram with the Journal name, volume number, and year stamped in gold on the spine. Payment must accompany all orders. Contact Mosby, Subscription Customer Service, 6277 Sea Harbor Dr, Orlando, FL 32887, USA; phone 800-654-2452 or 407-345-4000.

Subscriptions must be in force to qualify. Bound volumes are not available in place of a regular Journal subscription. 